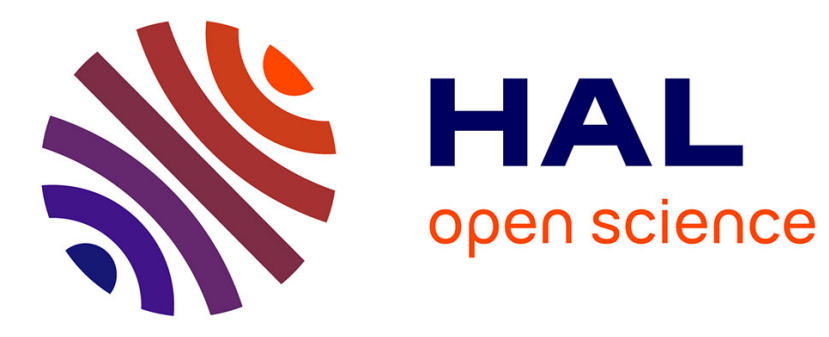

\title{
Gorillibacterium timonense sp. nov., isolated from an obese patient
}

Sokhna Ndongo, Mamadou Beye, Noemie Labas, Fabrizio Di Pinto, Magali Richez, Jean-Christophe J.-C. Lagier, Pierre-Edouard Fournier, Didier Raoult, Fadi Bittar

\section{To cite this version:}

Sokhna Ndongo, Mamadou Beye, Noemie Labas, Fabrizio Di Pinto, Magali Richez, et al.. Gorillibacterium timonense sp. nov., isolated from an obese patient. Archives of Microbiology, 2020, 10.1007/s00203-020-01834-x . hal-02502401

\section{HAL Id: hal-02502401 https: / hal-amu.archives-ouvertes.fr/hal-02502401}

Submitted on 17 Sep 2021

HAL is a multi-disciplinary open access archive for the deposit and dissemination of scientific research documents, whether they are published or not. The documents may come from teaching and research institutions in France or abroad, or from public or private research centers.
L'archive ouverte pluridisciplinaire HAL, est destinée au dépôt et à la diffusion de documents scientifiques de niveau recherche, publiés ou non, émanant des établissements d'enseignement et de recherche français ou étrangers, des laboratoires publics ou privés. 


\title{
Gorillibacterium timonense sp. nov., isolated from an obese patient
}

\author{
Sokhna Ndongo ${ }^{1,3} \cdot$ Mamadou Beye $^{1,3} \cdot$ Noémie Labas $^{1,3} \cdot$ Fabrizio Di Pinto $^{1,3} \cdot$ Magali Richez $^{1,3}$. \\ Jean-Christophe Lagier ${ }^{1,3} \cdot$ Pierre-Edouard Fournier ${ }^{2,3} \cdot$ Didier Raoult $^{1,3} \cdot$ Fadi Bittar $^{1,3}$ (1)
}

\begin{abstract}
A Gram-negative and facultative anaerobic bacterium, designated strain $\mathrm{SN} 4^{\mathrm{T}}$, was isolated from the stool sample of an obese Amazonian patient. The new isolate was characterized by the taxonogenomics approach. The strain SN4 ${ }^{\mathrm{T}}$ was beigecolored, circular and not haemolytic. Cells are rod shaped and motile with several flagella. Strain $\mathrm{SN} 4^{\mathrm{T}}$ grows optimally at $\mathrm{pH} 7$ and can survive in the presence of a saline concentration of up to $75 \mathrm{~g} / 1 \mathrm{NaCl}$. The $16 \mathrm{~S}$ ribosomal RNA gene sequence analysis of the novel strain $\mathrm{SN} 4^{\mathrm{T}}$ showed $95.28 \%$ similarity in nucleotide sequence with Gorillibacterium massiliense $\mathrm{G}^{\mathrm{T}}$, the phylogenetically closest neighbor and the type species of this genus. Anteiso- $\mathrm{C}_{15: 0}$, iso- $\mathrm{C}_{15: 0}$ and $\mathrm{C}_{16: 0}$ were found as the major components in the cellular fatty acid analysis of this isolate. The genomic draft of strain $\mathrm{SN}^{\mathrm{T}}$ is $5,263,742 \mathrm{bp}$ long with $53.33 \%$ of $\mathrm{G}+\mathrm{C}$ content. The differences in physiological, biochemical characteristics and phylogenetic and genomic data make it possible to clearly distinguish the strain $\mathrm{SN} 4^{\mathrm{T}}$ from G. massiliense $\mathrm{G} 5^{\mathrm{T}}$. Based on the taxonogenomic description and the phenotypic and biochemical characteristics of this bacterium presented in this article, we propose the $\mathrm{SN} 4^{\mathrm{T}}$ strain (=CSUR P2011 = DSM 100,698) as a new species, Gorillibacterium timonense sp. nov.
\end{abstract}

Keywords Gorillibacterium timonense $\cdot$ Genome $\cdot$ Taxonogenomics $\cdot$ Human gut microbiota

\section{Introduction}

The development of metagenomics has allowed, over the last 10 years, a better exploration of the intestinal microbiota and has demonstrated the relationship between altered gut microflora and several diseases such as obesity, inflammatory bowel disease and irritable bowel syndrome (Salazar et al. 2014). However, the composition of human gut microbiota and its relationship to the host, particularly with respect to

Fadi Bittar

fadi.bittar@univ-amu.fr

1 Aix Marseille Univ, IRD, APHM, MEPHI, Marseille, France

2 Aix Marseille Univ, IRD, APHM, SSA, VITROME, Marseille, France

3 Institut Hospitalo-Universitaire Méditerranée Infection, 19-21 Boulevard Jean Moulin, 13385 Marseille Cedex 05, France human health and disease, provides several challenges for microbiologists (Lagier et al. 2012b). Indeed, $1 \mathrm{~g}$ of a human stool sample contains between $10^{11}$ and $10^{12}$ bacteria (Raoult and Henrissat 2014), but only about 2000 different bacterial species are actually isolated from human microbiota. In this respect, and given the insufficient attention previously paid to culture methods, our laboratory has developed culturomics (Lagier et al. 2012a) to improve the isolation of bacteria from the human gut. Since the application of this technique in 2012, many novel genera and species have been isolated from the human gut. Moreover, for the description of these new bacteria, complete genome sequencing, matrix-assisted laser-desorption/ionization time-of-flight (MALDI-TOF) spectrum analysis of cellular proteins, cellular fatty acid methyl ester (FAME) analysis (Sasser 2006) and more traditional methods for phenotypic characterization have recently been developed (Ramasamy et al. 2014). This strategy, named taxonogenomics, has proven useful in describing new bacterial taxa (Ramasamy et al. 2014).

Among these new taxa, Gorillibacterium timonense strain SN4 (=CSUR P2011 = DSM 100,698) is a new member of the genus Gorillibacterium first described by Keita et al. (Keita et al. 2014). The genus Gorillibacterium belongs to 
the family Paenibacillaceae and the strain SN4 is the second species of this genus following the isolation of G. massiliense from the fecal flora of a gorilla.

We present here the isolation, a summary classification, phenotypic characteristics, as well as a description of the complete genome sequencing and annotation of the SN4 strain of G. timonense.

\section{Materials and methods}

\section{Sample information and strain isolation}

A stool sample was collected from an obese Amazonian man (45 years old; Manaus, Brazil) during a culturomics project exploring the human intestinal microbiota. An informed consent was obtained from the patient and the procedures were approved by the local ethics committee of the Institut Fédératif de Recherche 48 (Marseille, France) under the agreement number 09-022. The stool sample was conserved at $-80{ }^{\circ} \mathrm{C}$ at La Timone Hospital in Marseille until being investigated. Strain $\mathrm{SN} 4^{\mathrm{T}}$ was isolated in 2015 by cultivation on Columbia agar supplemented with 5\% sheep blood (BioMerieux, Marcy l'Etoile, France) in microaerophilic atmosphere generated by CampyGen (Oxoid, Dardilly, France) after $48 \mathrm{~h}$ at $37^{\circ} \mathrm{C}$. Briefly, $1 \mathrm{~g}$ of aliquot of the thawed stool was suspended in phosphate-buffered saline. $1 \mathrm{ml}$ of this suspension was diluted several times to the tenth. $50 \mu \mathrm{l}$ of each dilution was spread in Columbia agar plates and then incubated at $37{ }^{\circ} \mathrm{C}$ for $48 \mathrm{~h}$ under microaerophilic conditions. Isolated colonies were purified by individual subculture in the same type of culture medium in which they were first isolated.

\section{Strain identification by MALDI-TOF mass spectrometry (MS) and phylogenetic analysis}

MALDI-TOF MS analysis of proteins was performed for the identification of bacteria following the same protocol previously described (Lagier et al. 2012c). The generated spectra were then compared to the Bruker database, which is supplemented by spectra of new strains found by various cultural projects, including four Gorillibacterium massiliense $\mathrm{G} 5^{\mathrm{T}}$ spectra. The identification and discrimination of the analyzed strain depend on the score obtained by comparison with the BioTyper database spectra: a score $>2$ with a validated species enabled the identification at the species level; and a score $<1.7$ did not enable any identification. Following a failed identification of our strain by MALDITOF MS, sequencing of the $16 \mathrm{~S}$ ribosomal RNA gene was achieved as previously described (Drancourt et al. 2000). The 16S rRNA nucleotide sequence obtained was aligned and analyzed using the CodonCode Aligner software (https ://www.codoncode.com/). The BLAST nucleotide was then searched in the National Center for Biotechnology Information (NCBI) online database (https://blast.ncbi.nlm.nih.gov/ Blast.cgi). CLUSTAL W was used for sequences alignment of the different species and MEGA 7 (Molecular Evolutionary Genetics Analysis) software was used to construct the phylogenetic tree.

\section{Phenotypic, biochemical and chemotaxonomic analyses}

Different growth temperatures $\left(28^{\circ} \mathrm{C}, 37^{\circ} \mathrm{C}, 45^{\circ} \mathrm{C}, 55^{\circ} \mathrm{C}\right)$ were assessed for strain $\mathrm{SN} 4^{\mathrm{T}}$ by cultivating it on $5 \%$ sheep's blood-enriched Columbia agar (bioMérieux) under anaerobic and microaerophilic conditions using AnaeroGenTM and CampyGenTM, respectively (bioMérieux, ThermoFisher scientific). Growth was also tested aerobically with or without $5 \% \mathrm{CO}_{2}$. The salinity tolerance for strain $\mathrm{SN} 4^{\mathrm{T}}$ was tested using $0,5,25$ and $50 \% \mathrm{NaCl}$ concentrations and four $\mathrm{pH}$ values for growth were tested: 6, 6.5, 7 and 8.5. Gram staining and motility were observed from fresh colonies between blades and slats using a DM1000 photonic microscope (Leica Microsystems, Nanterre, France) with a $40 \times$ objective lens.

Spore formation was determined by a heat shock $\left(80^{\circ} \mathrm{C}\right.$ for $20 \mathrm{~min}$ ) and then subcultured on $5 \%$ sheep bloodenriched Columbia agar medium (bioMérieux). The $\mathrm{SN} 4^{\mathrm{T}}$ strain was analyzed by electron microscopy using Formvarcoated grids placed on a $40 \mu \mathrm{l}$ drop of bacterial suspension and incubated at $37{ }^{\circ} \mathrm{C}$ for $30 \mathrm{~min}$, followed by a $10 \mathrm{~s}$ incubation with ammonium molybdate. The grids were then dried on blotting paper and observed using a transmission electron microscope Tecnai G20 (FEI Company, LimeilBrévannes, France) at an operating voltage of $60 \mathrm{kV}$.

Biochemical characteristics of strain $\mathrm{SN} 4^{\mathrm{T}}$ and strain $\mathrm{G} 5^{\mathrm{T}}$ (Gorillibacterium massiliense) were obtained using the API ZYM strips, API 50CH and API 20NE performed according to the manufacturer's instructions (bioMérieux). Catalase and oxidase activities were determined using a BD BBL DrySlide (Becton, Dickinson, New Jersey, USA) according to the manufacturer's instructions. The antimicrobial activity test was performed by the disk diffusion method (Le Page et al. 2015) using 16 antibiotics including Ceftriaxone, Ciprofloxacin, Clindamycin, Colistin, Doxycycline, Erythromycin, Gentamycin, Oxacillin, Rifampicin, Penicillin, Teicoplanin, Trimethoprim-sulfamethoxazole, Vancomycin, Imipenem, Fosfomycin and Metronidazole. The discs used were purchased from i2a (Montpellier, France) and strain $\mathrm{SN} 4^{\mathrm{T}}$ was cultivated on Mueller-Hinton agar in a Petri dish (bioMérieux, Marcy-l'Etoile, France).

Cellular fatty acid methyl ester (FAME) analyses of this isolate and of $G$. massiliense strain $\mathrm{G} 5^{\mathrm{T}}$ were performed by gas chromatography/mass spectrometry (GC/MS) as 
Fig. 1 Phylogenetic tree highlighting the position of Gorillibacterium timonense strain $\mathrm{SN} 4^{\mathrm{T}}$ relative to the type species of the genus Gorillibac$\mathrm{G5}^{\mathrm{T}}$ ) and some other members of the family Paenibacillaceae. are indicated in parentheses. Sequences were aligned using CLUSTALW, and phylogenetic inferences obtained using the maximum-likelihood method within the MEGA 6 software. Numbers at the nodes are bootstrap values obtained by repeating the analysis 1000 times to generate a majority consensus tree. The scale bar indicates a $1 \%$ nucleotide sequence divergence terium ( $G$. massiliense strain GenBank accession numbers

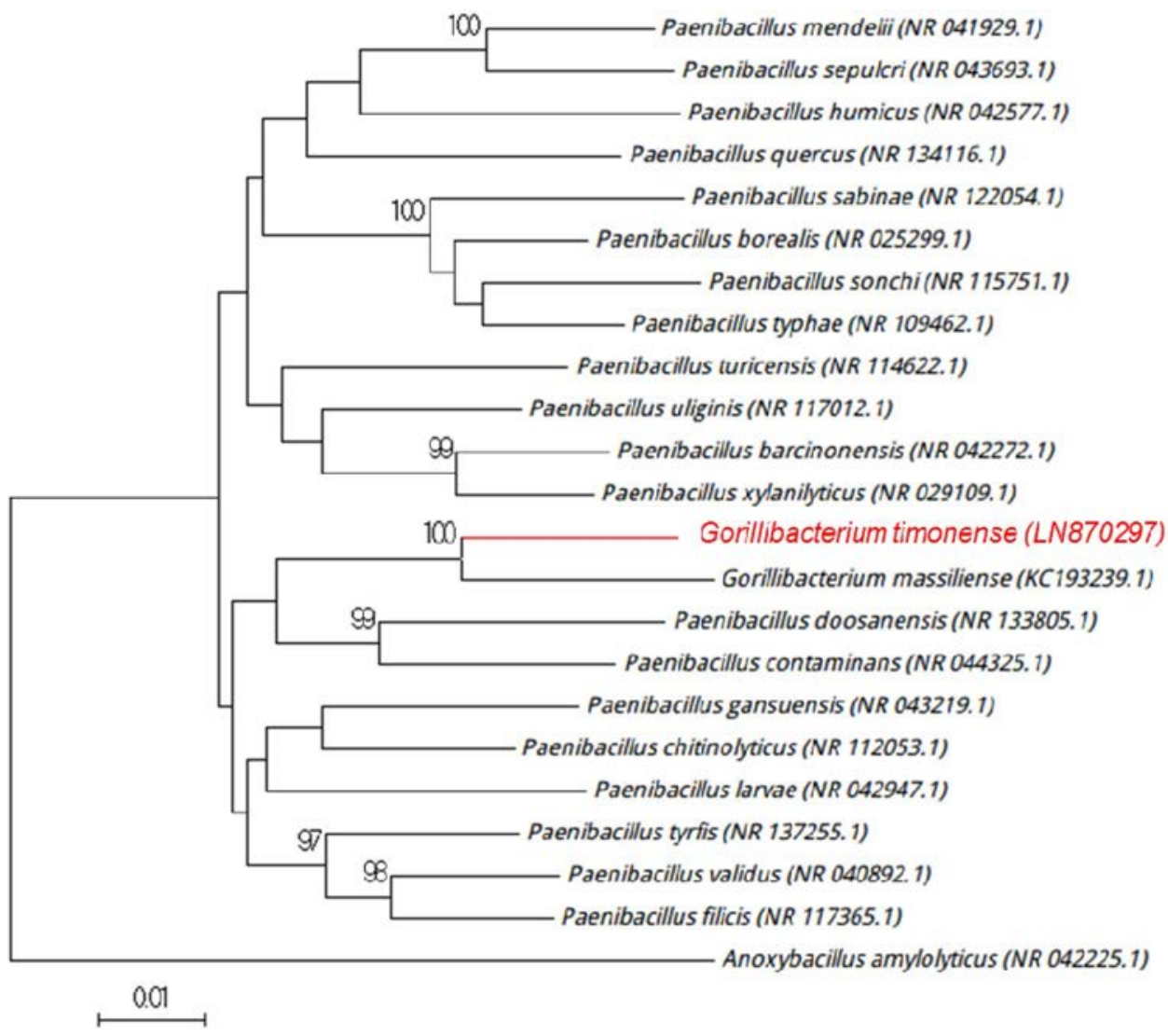

previously described by Dione et al. (Dione et al. 2016). Briefly, strain $\mathrm{SN} 4{ }^{\mathrm{T}}$ and strain $\mathrm{G} 5^{\mathrm{T}}$ were cultured on $5 \%$ sheep's blood-enriched Columbia agar (bioMérieux) under aerobic condition for $24 \mathrm{~h}$ at $37^{\circ} \mathrm{C}$. Approximately $100 \mathrm{mg}$ of bacterial biomass of each strain was collected from four different agar plates. Fatty acid methyl esters were then prepared as described by Sasser (2006), were separated using an Elite 5-MS column and were monitored by mass spectrometry (Clarus 500-SQ 8 S, Perkin Elmer, Courtaboeuf, France). Spectral database search was performed using MS Search 2.0 operated with the Standard Reference Database 1A (NIST, Gaithersburg, USA) and the FAME mass spectral database (Wiley, Chichester, UK).

\section{Genomic DNA preparation, genome sequencing and assembly}

Genomic DNA (gDNA) from strain $\mathrm{SN} 4^{\mathrm{T}}$ was extracted using the EZ1 biorobot (Qiagen, Courtaboeuf, France) with EZ1 DNA tissue kit as previously described (Abou Abdallah et al. 2017). gDNA was sequenced on the MiSeq sequencer (Illumina Inc, San Diego, CA, USA) with the mate pair sequencing strategy as previously described (Abou Abdallah et al. 2017). The genome's assembly was performed as previously described (Abou Abdallah et al. 2017) using a pipeline which made it possible to create an assembly with different evich et al. 2012) and Soap Denovo (Luo et al. 2012)], on trimmed [MiSeq and Trimmomatic software (Bolger et al. 2014)] or untrimmed data (only MiSeq software).

GapCloser (Luo et al. 2012) was used to reduce gaps for each of the assemblies performed. Then contamination with Phage Phix was identified (blastn against Phage Phix174 DNA sequence) and eliminated. In the end, scaffolds with a size of less than $800 \mathrm{bp}$ were removed and scaffolds with a depth value of less than $25 \%$ of the average depth were identified as possible contaminants and removed.

\section{Genome annotation and comparison}

Open Reading Frames (ORFs), ORFans, tRNA genes, ribosomal RNAs and other nucleotide contents have been identified using the tools and settings as was previously described by Abou Abdallah et al. (2019).

Comparative genomic analysis was realized between the genome of strain $\mathrm{SN} 4^{\mathrm{T}}$ and the genome of $G$. massiliense strain G5 ${ }^{\mathrm{T}}$ (CBQR00000000). Two parameters were used to evaluate the genomic similarity between the two studied Gorillibacterium strains: digital DNA-DNA hybridization (dDDH) that exhibits a high correlation with DDH (Auch et al. 2010; Meier-Kolthoff et al. 2013a) and OrthoAni softwares [Velvet (Zerbino and Birney 2008), Spades (Bank- 
Table 1 Differential characteristics of Gorillibacterium timonense strain $\mathrm{SN} 4^{\mathrm{T}}$ with Gorillibacterium massiliense strain $\mathrm{G} 5^{\mathrm{T}}$

\begin{tabular}{lll}
\hline Properties & $\begin{array}{l}\text { Gorillibacterium } \\
\text { timonense } \text { strain } \\
\text { SN4 }\end{array}$ & $\begin{array}{l}\text { Gorillibacterium } \\
\text { massiliense }^{\mathrm{G}} \text { Grain }\end{array}$ \\
\hline Motility & + & - \\
Endospore formation & + & - \\
Catalase & - & + \\
Esterase & + & - \\
Esterase lipase & + & - \\
L-Arginine & - & + \\
Urease & - & + \\
$\beta$-Galactosidase & + & - \\
D-Glucose & - & + \\
L-Arabinose & - & + \\
D-Mannose & - & + \\
$N$-Acetyl-glucosamine & - & + \\
D-Maltose & - & + \\
D-Ribose & + & - \\
D-Fructose & - & + \\
D-Galactose & + & - \\
Amygdalin & + & - \\
Salicin & - & + \\
Inulin & - & + \\
Xylitol & - & + \\
D-Xylose & - & + \\
\hline
\end{tabular}

$+=$ positive $;-=$ negative

which is a software for calculating average nucleotide identity (ANI) (Lee et al. 2016).

\section{Strain and sequence deposition}

Strain SN4 ${ }^{\mathrm{T}}$ has been deposited in two microbial culture collections: the German collection of microorganisms (Deutsche Sammlung von Mikroorganismen und Zellkulturen, DSMZ), under the accession number DSM 100,698, and the French culture collection (Collection de Souches de l'Unité des Rickettsies, CSUR), under the accession number CSUR P2011. The 16S rRNA gene and genome sequences are deposited in EMBL-EBI under the accession numbers LN870297 and CYUM00000000, respectively. The Digital Protologue database (https://imedea.uib-csic.es/dprotologu e) taxon number for strain SN4T is TA00778.

\section{Results and discussion}

\section{Strain identification and phylogenetic analyses}

Strain $\mathrm{SN} 4^{\mathrm{T}}$ was first isolated in 2015 by the cultivation of a stool sample from an obese Amazonian patient on 5\% sheep
Table 2 Cellular fatty acids composition for Gorillibacterium timonense strain $\mathrm{SN}^{\mathrm{T}}$ and for Gorillibacterium massiliense strain $\mathrm{G} 5^{\mathrm{T}}$

\begin{tabular}{|c|c|c|c|}
\hline Fatty acids & IUPAC name & $\begin{array}{l}\text { G. timonense } \\
\text { strain SN4 }^{\mathrm{Ta}}\end{array}$ & $\begin{array}{l}\text { G. massil- } \\
\text { iense strain } \\
\mathrm{G5}^{\mathrm{Ta}}\end{array}$ \\
\hline $15: 0$ anteiso & $\begin{array}{l}\text { 12-Methyl-tetradecanoic } \\
\text { acid }\end{array}$ & $38.0 \pm 2.3$ & $66.7 \pm 0.9$ \\
\hline $15: 0$ iso & $\begin{array}{l}\text { 13-Methyl-tetradecanoic } \\
\text { acid }\end{array}$ & $24.0 \pm 1.5$ & $4.9 \pm 0.1$ \\
\hline $16: 00$ & Hexadecanoic acid & $16.9 \pm 1.4$ & $11.9 \pm 0.7$ \\
\hline $18: \ln 9$ & 9-Octadecenoic acid & $5.0 \pm 0.8$ & TR \\
\hline $14: 00$ & Tetradecanoic acid & $4.2 \pm 0.5$ & $1.2 \pm 0.1$ \\
\hline 18:00 & Octadecanoic acid & $2.7 \pm 0.1$ & TR \\
\hline $14: 0$ iso & $\begin{array}{l}\text { 12-Methyl-tridecanoic } \\
\text { acid }\end{array}$ & $2.0 \pm 0.1$ & $\mathrm{TR}$ \\
\hline $16: 0$ iso & $\begin{array}{l}\text { 14-Methyl-pentadecanoic } \\
\text { acid }\end{array}$ & $1.7 \pm 0.2$ & $5.3 \pm 0.2$ \\
\hline $15: 00$ & Pentadecanoic acid & $\mathrm{TR}$ & $1.4 \pm 0.1$ \\
\hline 13:0 anteiso & $\begin{array}{l}\text { 10-Methyl-dodecanoic } \\
\text { acid }\end{array}$ & TR & $\mathrm{NF}$ \\
\hline 17:0 anteiso & $\begin{array}{l}\text { 14-Methyl-hexadecanoic } \\
\text { acid }\end{array}$ & TR & $4.9 \pm 0.1$ \\
\hline $18: 2 \mathrm{n} 6$ & $\begin{array}{l}\text { 9,12-Octadecadienoic } \\
\text { acid }\end{array}$ & TR & $\mathrm{TR}$ \\
\hline $17: 0$ iso & $\begin{array}{l}\text { 15-Methyl-hexadecanoic } \\
\text { acid }\end{array}$ & $\mathrm{TR}$ & $\mathrm{TR}$ \\
\hline $18: 1 \mathrm{n} 6$ & 12-Octadecenoic acid & $\mathrm{TR}$ & $\mathrm{TR}$ \\
\hline $16: 1 n 7$ & 9-Hexadecenoic acid & $\mathrm{TR}$ & $\mathrm{TR}$ \\
\hline $17: 00$ & Heptadecanoic acid & TR & $\mathrm{NF}$ \\
\hline 5:0 anteiso & 2-Methyl-butanoic acid & $\mathrm{TR}$ & $\mathrm{NF}$ \\
\hline $12: 00$ & Dodecanoic acid & TR & NF \\
\hline $13: 0$ iso & $\begin{array}{l}\text { 11-Methyl-dodecanoic } \\
\text { acid }\end{array}$ & TR & TR \\
\hline
\end{tabular}

$T R$ trace amounts $<1 \%, N F$ not found

${ }^{\mathrm{a}}$ Mean relative $\% \pm \mathrm{SD}$

blood agar under microaerophilic conditions. The spectrum generated from clean strain SN4 ${ }^{\mathrm{T}}$ (Supplementary Fig. 1), following MALDI-TOF MS analysis, displayed an identification score of 1.3 , which suggested that the spectrum was unknown in our database, indicating that the strain could be a new species. The $16 \mathrm{~S}$ ribosomal RNA gene sequence of strain $\mathrm{SN}^{\mathrm{T}}{ }^{\mathrm{T}}$ (GenBank accession number LN870297) showed $95.3 \%$ similarity with the nucleotide sequence of Gorillibacterium massiliense $\mathrm{G}^{\mathrm{T}}{ }^{\mathrm{T}}$ (GenBank accession number NR_146838) (Fig. 1). The second closest species was a member of Paenibacillus genus (Paenibacillus turicensis strain MOL722, 93.13\%). This value of similarity was lower than the 98.7\% 16S rRNA gene sequence threshold recommended by Stackebrandt and Ebers to delineate a new species (Stackebrandt and Ebers 2006) and without the need for carrying out DDH according to the recommendation of Meier-Kolthoff et al. for Firmicutes, with a maximum error 
Table 3 Nucleotide content and gene count levels of the genome of G. timonense strain $\mathrm{SN} 4^{\mathrm{T}}$

\begin{tabular}{lll}
\hline Attribute & \multicolumn{2}{l}{ Genome (total) } \\
\cline { 2 - 3 } & Value & Total $(\%)^{\mathrm{a}}$ \\
\hline Size (bp) & $5,263,742$ & 100 \\
G+C content (\%) & $2,807,257$ & 53.33 \\
Coding region (bp) & $4,561,907$ & 86.66 \\
Total genes & 4778 & 100 \\
RNA genes & 68 & 1.42 \\
Protein-coding genes & 4712 & 100 \\
Genes with function prediction & 3261 & 69.23 \\
Genes assigned to COGs & 2797 & 59.38 \\
Genes with peptide signals & 613 & 13.01 \\
Genes with transmembrane helices & 1105 & 23.46 \\
Genes associated to toxin/antitoxin & 134 & 2.84 \\
ORFn genes & 301 & 6.39 \\
Genes associated with PKS or NRPS & 9 & 0.19 \\
\hline
\end{tabular}

${ }^{\mathrm{a}}$ The total is based on either the size of the genome in base pairs or the total number of protein-coding genes in the annotated genome

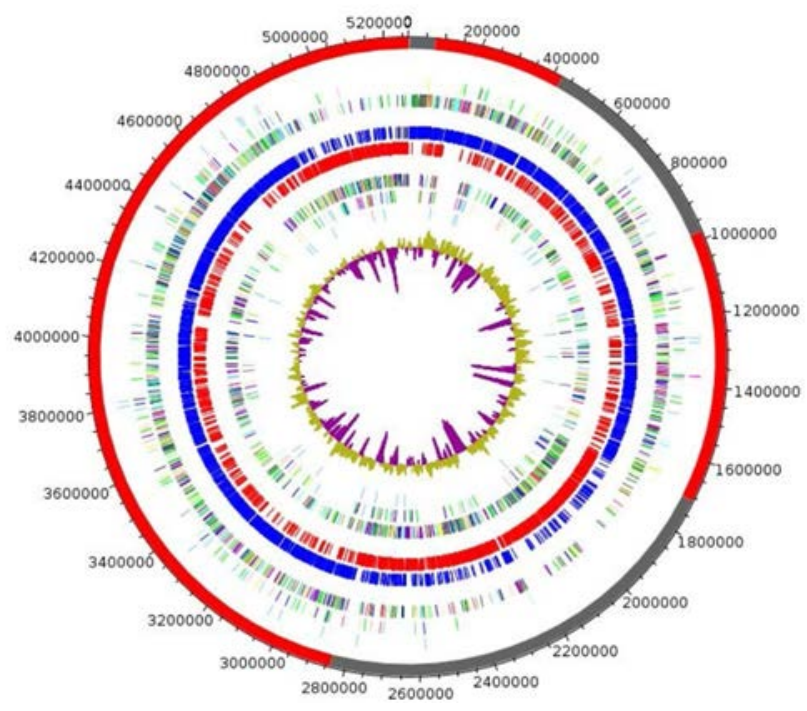

Fig. 2 Graphical circular map of the genome of Gorillibacterium timonense strain $\mathrm{SN}^{\mathrm{T}}{ }^{\mathrm{T}}$. From outside to the center: contigs (red/grey), COG category of genes on the forward strand (three circles), genes on forward strand (blue circle), genes on the reverse strand (red circle), COG category on the reverse strand (three circles), GC content

probability of $0.01 \%$ (Meier-Kolthoff et al. 2013b). Based on these results, strain $\mathrm{SN} 4{ }^{\mathrm{T}}$ was thus classified as a putative new species of the genus Gorillibacterium and named Gorillibacterium timonense. The reference spectrum was then added to our database (Supplementary Fig. 1) (https ://www.mediterranee-infection.com/article.php?larub $=280 \&$ titre $=$ urms-database) and the gel view highlighted the differences with $G$. massiliense $\mathrm{G5}^{\mathrm{T}}$, the first member of the genus Gorillibacterium (Supplementary Fig. 2).

\section{Phenotypic, biochemical and chemotaxonomic analyses}

Although strain $\mathrm{SN} 4{ }^{\mathrm{T}}$ was first isolated under microaerophilic condition, it grows better under aerobic condition on $5 \%$ sheep's blood-enriched Columbia agar at $37{ }^{\circ} \mathrm{C}$ after $24 \mathrm{~h}$. Bacterial growth, morphology, antimicrobial susceptibility testing and biochemical characteristics for strain $\mathrm{SN} 4^{\mathrm{T}}$ are detailed in the description of the species, Supplementary Table 1, Supplementary Fig. 3).

The main phenotypic and biochemical differences of strain $\mathrm{SN}^{\mathrm{T}}$ compared with $G$. massiliense strain $\mathrm{G} 5^{\mathrm{T}}$ are presented in Table 1. Analysis of cellular FAMEs shows that the most abundant fatty acids are unsaturated: 12-methyl-tetradecanoic acid (38\%), 13-methyl-tetradecanoic acid (24\%) and hexadecanoic acid (17\%) (Table 2). Almost half of the described fatty acids are branched (iso or anteiso). Cellular fatty acid profile of strain $\mathrm{SN} 4^{\mathrm{T}}$ compared to this of $G$. massiliense strain $5^{\mathrm{T}}$ is presented in Table 2.

\section{Genome properties}

The genome is $5,263,742$ bp long with $53.33 \%$ of $\mathrm{G}+\mathrm{C}$ content (Table 3, Fig. 2). It is composed of seven scaffolds (composed of nine contigs). Of the 4,778 predicted genes, 4,710 were protein-coding genes and 68 were RNAs (5 genes are $5 \mathrm{~S}$ rRNA, 1 gene is $16 \mathrm{~S}$ rRNA, 1 gene is $23 \mathrm{~S}$ rRNA, 61 genes are tRNA genes). A total of 3,261 genes (69.24\%) were assigned as putative function (by cogs or by NR BLAST) (Supplementary Table 2). 301 genes were identified as ORFans (6.39\%) and 964 genes were annotated as hypothetical proteins $(20.47 \%)$.

\section{Genome comparison}

The draft genome sequence of strain $\mathrm{SN} 4^{\mathrm{T}}$ is smaller than that of Gorillibacterium massiliense strain $\mathrm{G}^{\mathrm{T}}$ (5.26 MB vs 5.55 MB, respectively). The $\mathrm{G}+\mathrm{C}$ content of strain $\mathrm{SN} 4^{\mathrm{T}}$ is higher than that of G. massiliense strain $\mathrm{G}^{\mathrm{T}}$ (53.33\% vs $50.39 \%$, respectively). The gene content of strain $\mathrm{SN} 4{ }^{\mathrm{T}}$ is lower than that of G. massiliense strain $\mathrm{G}^{\mathrm{T}}$ (4,778 vs 5,151 , respectively). A similar distribution of genes into COG categories was observed between the 2 compared genomes (Fig. 3). dDDH estimation of strain $\mathrm{SN}^{\mathrm{T}}$ against G. massiliense strain $\mathrm{G}^{\mathrm{T}}$ is $20.8 \%$ [18.5-23.2\%]. This value is very low and below the $70 \%$ threshold used for species delineation in the classification of prokaryotes. The ANI value between the genome of 


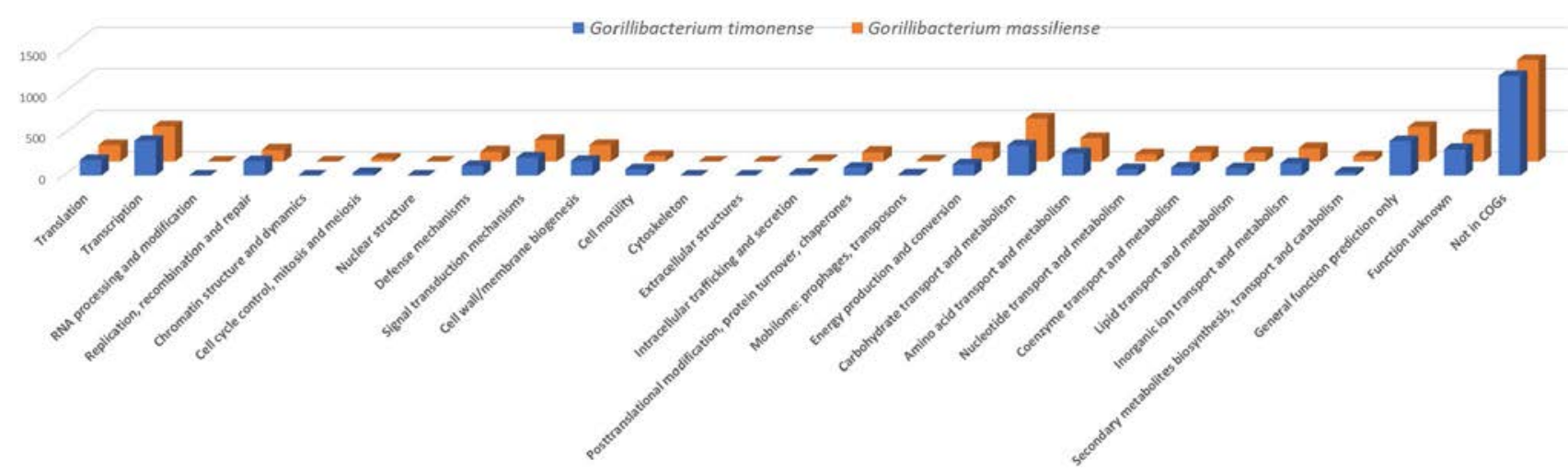

Fig. 3 Distribution of functional classes of predicted genes according to the clusters of orthologous groups of proteins of Gorillibacterium timonense strain $\mathrm{SN} 4^{\mathrm{T}}$ and Gorillibacterium massiliense strain $\mathrm{G} 5^{\mathrm{T}}$

strain $\mathrm{SN} 4^{\mathrm{T}}$ and the genome of G. massiliense strain $\mathrm{G} 5^{\mathrm{T}}$ is $70.24 \%$. This value is also below the $96 \%$ ANI cutoff for species circumscription (Ciufo et al. 2018), confirming again the status of strain $\mathrm{SN} 4^{\mathrm{T}}$ as a new species.

\section{Taxonogenomic conclusion}

The phylogenetic and genomic distances between strain $\mathrm{SN} 4^{\mathrm{T}}$ and the only type species of the genus Gorillibacterium together with the combination of unique phenotypic characteristics indicate that strain $\mathrm{SN}^{\mathrm{T}}$ represents a novel species of the genus Gorillibacterium, for which the name Gorillibacterium timonense sp. nov. is formally proposed. This bacterial strain has been isolated from the fecal flora of an obese Amazonian patient.

\section{Description of Gorillibacterium timonense sp. nov.}

Gorillibacterium timonense (ti.mo.nen'se NL adj neut, timonense of Timone, the main hospital of Marseille where strain $\mathrm{SN} 4^{\mathrm{T}}$ was first cultivated).

A facultative anaerobic, mesophilic and Gram-negative bacterium. Cells are rod shaped with a mean diameter of $0.6 \mu \mathrm{m}$ and a length of $1.8-2.5 \mu \mathrm{m}$. Catalase and oxidase negative. Colonies are circular, beige, smooth and not haemolytic on $5 \%$ sheep blood-enriched Columbia agar. Optimal growth occurs at $37{ }^{\circ} \mathrm{C}$ with $0-75 \mathrm{~g} / \mathrm{l}$ of $\mathrm{NaCl}$ and at $\mathrm{pH} 7-8.5$. Using API 20NE system, a positive reaction was obtained for esculin hydrolysis and $\beta$-galactosidase. Using API ZYM, positive reactions were observed for esterase, esterase lipase, naphthol-AS-BI-phosphohydrolase, $\alpha$-galactosidase and $\beta$-galactosidase. Using API $50 \mathrm{CH}$ strip, strain $\mathrm{SN}^{\mathrm{T}}$ showed positive reactions for the fermentation of L-arabinose, D-xylose, methyl- $\beta$ D-xylopyranoside, D-galactose, D-glucose, D-fructose, D-mannose, methyl$\alpha$ D-glucopyranoside, $N$-acetylglucosamine, amygdalin, esculin, D-cellobiose, D-maltose, D-lactose, D-melibiose, D-saccharose, D-trehalose, D-raffinose, starch, glycogen, gentiobiose and D-turanose. Cells are susceptible to ceftriaxone, ciprofloxacin, clindamycin, colistin, doxycycline, erythromycin, gentamicin, oxacillin, rifampicin, penicillin, teicoplanin, trimethoprim-sulfamethoxazole, vancomycin and imipenem, but resistant to fosfomycin and metronidazole. 12-methyl-tetradecanoic acid (38\%), 13-methyltetradecanoic acid $(24 \%)$ and hexadecanoic acid $(17 \%)$ are the major components of the cellular fatty acid profile of strain $\mathrm{SN} 4{ }^{\mathrm{T}}$. The $\mathrm{G}+\mathrm{C}$ content of the genome is $53.33 \%$. The type strain is Gorillibacterium timonense strain $\mathrm{SN} 4^{\mathrm{T}}$ $(=$ CSUR P2011 = DSM 100,698) and was isolated from a stool sample of an obese Amazonian man (45 years old; Manaus, Brazil).

Acknowledgements This work was supported by the IHU Méditerranée Infection (Marseille, France) and by the French Government under the "Investissements d'avenir" (Investments for the Future) program managed by the Agence Nationale de la Recherche (ANR, fr: National Agency for Research) (reference: Méditerranée Infection 10-IAHU-03). This work was also supported by Région ProvenceAlpes-Côte d'Azur and European funding FEDER PRIMI.

\section{References}

Abou Abdallah R, Cimmino T, Baron S et al (2017) Description of Chryseobacterium timonianum sp. nov., isolated from a patient with pneumonia. Antonie Van Leeuwenhoek 1:1-12. https://doi. org/10.1007/s10482-017-0885-8

Abou Abdallah R, Bou Khalil J, Andrieu C et al (2019) Draft genome and description of Cohnella massiliensis sp. nov., a new bacterial species isolated from the blood culture of a hemodialysis patient. Arch Microbiol 201:305-312. https://doi.org/10.1007/s0020 3-018-1612-1

Auch AF, von Jan M, Klenk H-P, Göker M (2010) Digital DNADNA hybridization for microbial species delineation by means of genome-to-genome sequence comparison. Stand Genomic Sci 2:117-134. https://doi.org/10.4056/sigs.531120 
Bankevich A, Nurk S, Antipov D et al (2012) SPAdes: a new genome assembly algorithm and its applications to single-cell sequencing. J Comput Biol J Comput Mol Cell Biol 19:455-477. https://doi. org/10.1089/cmb.2012.0021

Bolger AM, Lohse M, Usadel B (2014) Trimmomatic: a flexible trimmer for Illumina sequence data. Bioinforma Oxf Engl 30:2114 2120. https://doi.org/10.1093/bioinformatics/btu170

Ciufo S, Kannan S, Sharma S et al (2018) Using average nucleotide identity to improve taxonomic assignments in prokaryotic genomes at the NCBI. Int J Syst Evol Microbiol 68:2386-2392. https://doi.org/10.1099/ijsem.0.002809

Dione N, Sankar SA, Lagier J-C et al (2016) Genome sequence and description of Anaerosalibacter massiliensis sp. nov. New Microbes New Infect 10:66-76. https://doi.org/10.1016/j. nmni.2016.01.002

Drancourt M, Bollet C, Carlioz A et al (2000) 16S ribosomal DNA sequence analysis of a large collection of environmental and clinical unidentifiable bacterial isolates. J Clin Microbiol 38:3623-3630

Keita MB, Padhmanabhan R, Caputo A et al (2014) Non-contiguous finished genome sequence and description of Gorillibacterium massiliense gen. nov, sp. nov., a new member of the family Paenibacillaceae. Stand Genomic Sci 9:807-820. https://doi. org/10.4056/sigs.5199182

Lagier J-C, Armougom F, Million M et al (2012a) Microbial culturomics: paradigm shift in the human gut microbiome study. Clin Microbiol Infect Off Publ Eur Soc Clin Microbiol Infect Dis 18:1185-1193. https://doi.org/10.1111/1469-0691.12023

Lagier J-C, Million M, Hugon P et al (2012b) Human gut microbiota: repertoire and variations. Front Cell Infect Microbiol 2:136. https ://doi.org/10.3389/fcimb.2012.00136

Lagier J-C, Ramasamy D, Rivet R et al (2012c) Non contiguousfinished genome sequence and description of Cellulomonas massiliensis sp. nov. Stand Genomic Sci 7:258-270. https://doi. org/10.4056/sigs.3316719

Le Page S, van Belkum A, Fulchiron C et al (2015) Evaluation of the PREVI ${ }^{\circledR}$ Isola automated seeder system compared to reference manual inoculation for antibiotic susceptibility testing by the disk diffusion method. Eur J Clin Microbiol Infect Dis Off Publ Eur Soc Clin Microbiol 34:1859-1869. https://doi.org/10.1007/s1009 6-015-2424-8
Lee I, Ouk Kim Y, Park SC et al (2016) OrthoANI: An improved algorithm and software for calculating average nucleotide identity. Int J Syst Evol Microbiol 66:1100-1103. https://doi.org/10.1099/ ijsem.0.000760

Luo R, Liu B, Xie Y et al (2012) SOAPdenovo2: an empirically improved memory-efficient short-read de novo assembler. GigaScience 1:18. https://doi.org/10.1186/2047-217X-1-18

Meier-Kolthoff JP, Auch AF, Klenk H-P, Göker M (2013a) Genome sequence-based species delimitation with confidence intervals and improved distance functions. BMC Bioinf 14:60. https://doi. org/10.1186/1471-2105-14-60

Meier-Kolthoff JP, Göker M, Spröer C, Klenk H-P (2013b) When should a DDH experiment be mandatory in microbial taxonomy? Arch Microbiol 195:413-418. https://doi.org/10.1007/s0020 3-013-0888-4

Ramasamy D, Mishra AK, Lagier J-C et al (2014) A polyphasic strategy incorporating genomic data for the taxonomic description of novel bacterial species. Int J Syst Evol Microbiol 64:384-391. https://doi.org/10.1099/ijs.0.057091-0

Raoult D, Henrissat B (2014) Are stool samples suitable for studying the link between gut microbiota and obesity? Eur J Epidemiol 29:307-309. https://doi.org/10.1007/s10654-014-9905-4

Salazar N, Arboleya S, Valdés L et al (2014) The human intestinal microbiome at extreme ages of life: dietary intervention as a way to counteract alterations. Front Genet 5:406. https://doi. org/10.3389/fgene.2014.00406

Sasser M (2006) Bacterial identification by gas chromatographic analysis of fatty acid methyl esters (GC-FAME). Newark NY Microb ID

Stackebrandt E, Ebers J (2006) Taxonomic parameters revisited: tarnished gold standards. Microb Today 152-155

Zerbino DR, Birney E (2008) Velvet: algorithms for de novo short read assembly using de Bruijn graphs. Genome Res 18:821-829. https ://doi.org/10.1101/gr.074492.107 